\title{
Estimativa da penetração de íons cloretos no concreto autocicatrizante
}

\author{
MARIANA SILVA FERREIRA - ENGENHEIRA* \\ Centro Universitário do Instituto Mauá de Tecnologia - \\ IMT, Universidade Federal do ABC - UFABC
}

\begin{tabular}{|c|}
\hline GUSTAVO LOMBARDO - ENGENHEIRO \\
\hline CÁSSIA SILVEIRA DE ASSIS - Doutora e CoORdenadora dA Engenharia CIVIL \\
\hline MARCOS LUI GEH - ENGENHEIRO \\
\hline
\end{tabular}

EMILIO MINORU TAKAGI - Mestre E DIRetor TÉcnICO

Penetron Internacional, Instituto Tecnológico de Aeronáutica - ITA

\section{RESUMO}

CONCRETOS AUTOCICATRIZANTES SÃO CAPAZES DE SELAR SUAS FISSURAS, REDUZINDO AS TAXAS DE PENETRAÇÃO DE AGENTES AGRESSIVOS, COMO OS ÍONS CLORETOS, COMUNS EM ÁGUAS SALGADAS. A PENETRAÇÃO DOS IONS CLORETOS FOI ESTUDADA PARA O CONCRETO AUTOCICATRIZANTE, PREPARADO COM ADITIVO REDUTOR DE PERMEABILIDADE POR CRISTALIZAÇÃO CAPILAR, E PARA O GRUPO DE CONTROLE. DOIS MÉTODOS DE CURA FORAM UTILIZAdOS, SENDO ELES: PROCEDIMENTO LABORATORIAL, EM CÂMARA ÚMIDA OU CURA CÍCLICA, OU A REPRODUÇÃO DA CONDIÇÃO IN SITU,
COM FISSURAÇÃO E CURA EM CONDIÇÃO AMBIENTE OU COM CURA CÍCLICA. A PENETRAÇÃO DOS ÍONS CLORETOS FOI MENOR PARA O CONCRETO AUTOCICATRIZANTE EM COMPARAÇÃO AO GRUPO DE CONTROLE PARA AS MESMAS CONDIÇÕES DE CURA. A CURA CÍCLICA REDUZIU A PROFUNDIDADE DE PENETRAÇÃO PARA TODAS AS AMOSTRAS, INDEPENDENTEMENTE DO ADITIVO, DESTACANDO A IMPORTÂNCIA DA ÁGUA PARA A AUTOCICATRIZAÇÃO. A UTILIZAÇÃO DO ADITIVO PROPORCIONOU UMA REDUÇÃO DA PENETRABILIDADE E AUMENTO DA DURABILIDADE DO CONCRETO.

Palavras-chave: aditivo redutor de permeabilidade por cristalização capilar, durabilidade, água salgada, fissuras, métodos de cura.

\section{INTRODUÇÃO}

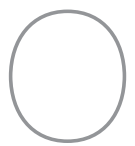

Brasil é conhecido mundialmente por seu longo litoral, possuindo uma alta densidade populacional nessa região. Diante disso, as construções devem ser adequadas para a agressividade desse ambiente, levando em consideração que a proximidade com a água salgada tem um grande impacto nos materiais utilizados, incluindo o concreto armado. Águas salgadas possuem alta concentração de íons cloretos, capazes de penetrar na estrutura construída e corroer a armação do concreto. Com a corrosão dessas barras, ocorre uma expan- são que fissura o concreto, danificando o cobrimento e expondo ainda mais a armação, aumentando a corrosão.

A penetração de íons cloretos nas estruturas de concreto ocorrem principalmente pelas fissuras presentes na superfície. Essas fissuras são inevitáveis, devido à baixa resistência à tração do material, e devem ser contidas para diminuir os danos na estrutura. Essa condição gera um grande interesse pelo concreto autocicatrizante, que possui a capacidade de selar as fissuras estreitas e reduzir a permeabilidade do material.

Todo concreto pode se autocicatrizar através de processos autógenos, sendo possível selar as fissuras por hidratação posterior de partículas de cimento não hidratado, inchaço de partículas ou produção de carbonato de cálcio [1]. A autocicatrização autônoma é baseada nos processos autógenos. É uma forma de autocicatrização induzida que pode ser provocada ao adicionar produtos específicos ao concreto, como, por exemplo, o aditivo redutor de permeabilidade por cristalização capilar. Esse tipo de aditivo já é utilizado comercialmente e pode ser encontrado em construções como, por exemplo, o subsolo de um prédio em Salvador (Brasil), que está em contato direto com as águas da Baía de Todos

*mariana.ferreira@maua.br 
os Santos [2], e o novo aeroporto internacional do México (NAIM), construído em uma área com alta concentração de cloreto e sulfato [3].

Muitos estudos recentes se concentraram em possíveis mudanças nas propriedades do concreto autocicatrizante. Helene et al. [4] focaram em diferentes relações de água/cimento, concluindo que o uso desse aditivo não altera as propriedades do concreto fresco e endurecido, como a trabalhabilidade e a resistência à compressão, além de comprovar um aumento na durabilidade do material.

Outros estudos demonstram reduções tanto na permeabilidade do concreto autocicatrizante quanto na frequência e necessidade de manutenção dessas estruturas. Todos esses fatores estão diretamente relacionados a melhoria da durabilidade discutida anteriormente. Alguns pontos relevantes para o estudo desse material foram discutidos, como, por exemplo, a necessidade de períodos de cura superiores a 56 dias e a importância da água no processo de autocicatrização, com melhores resultados para cura cíclica, que é uma cura úmida alternada com a cura seca $[1,3,5]$.

Avaliou-se a penetração de íons cloretos no concreto autocicatrizante exposto a diferentes tipos de cura. Foram realizadas duas configurações principais, uma focada no procedimento laboratorial e outra reproduzindo as condições encontradas in situ, com fissuração das amostras. Ambos foram comparados com a cura cíclica. Foi possível compreender a conexão entre o tipo de cura e o uso do aditivo redutor de permeabilidade por cristalização capilar.

\section{MATERIAIS $\in$ MÉTODOS}

O mesmo traço unitário, em massa, foi utilizado para todas as amostras

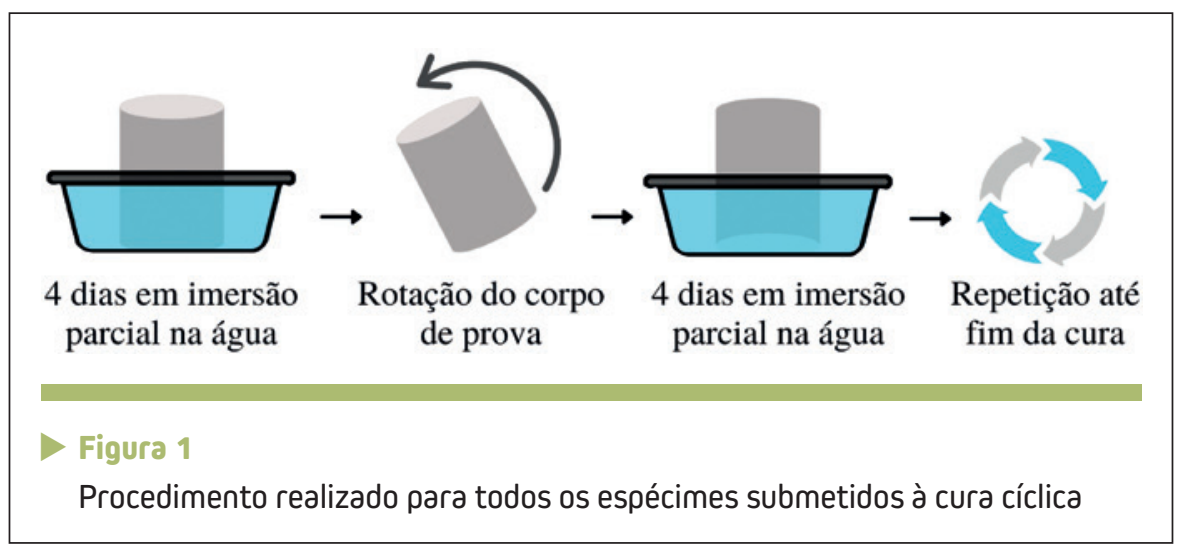

de concreto. Tendo a proporção de 1: 1,80: 0,81: 1,89: 0,52 sendo, respectivamente, cimento, areia, brita 0 , brita 1 e a relação água/cimento. O consumo de cimento para esse traço foi de $392,57 \mathrm{~kg} /$ $\mathrm{m}^{3}$. Os materiais utilizados na produção do concreto de controle foram o cimento Portland CPII E 32-RS MIZU, de Mogi das Cruzes (Brasil), areia lavada média, brita 0 , brita 1 e aditivo redutor de água tipo 2 (RA2), com dosagem sobre a massa de cimento de 0,35\%, todos de São Paulo (Brasil). Para o concreto autocicatrizante foi adicionada uma porcentagem sobre a massa de cimento de $0,8 \%$ do aditivo redutor de permeabilidade por cristalização capilar comercial (Lorena, Brasil) incluído durante a mistura do concreto. Nenhuma modificação foi feita no cimento e nos dois aditivos. Os agregados foram secos antes da mistura.

Todos os experimentos utilizaram amostras moldadas em formas cilíndricas, com dimensões de $10 \mathrm{~cm} \mathrm{x}$ $20 \mathrm{~cm}$. Os tipos de cura foram separados em duas configurações relacionadas ao procedimento laboratorial (LB) e à reprodução da condição in situ (IS). Foram utilizadas nessas configurações a cura em câmara úmida, cíclica e em condições ambiente, sendo que a cura cíclica foi a única realizada tanto para LB quanto para
IS. Essa cura cíclica, descrita na Figura 1, consistiu em deixar o corpo de prova parcialmente imerso na água, enquanto sua outra metade permaneceu em contato com o ar. Essa disposição foi mantida por 4 dias, sendo alternada por mais 4 dias, com repetição do ciclo até que o tempo de cura total foi atingido.

Os procedimentos para cada configuração de cura estão representados na Figura 2. A cura LB teve duração de 58 dias, incluindo o grupo cíclico (LB.C) e da câmara úmida (LB.U). Para a cura IS, as amostras foram fissuradas aos 28 dias, com 90\% de carga de ruptura, entre 42 e $43 \mathrm{MPa}$, permanecendo mais 28 dias em cura, metade em cura cíclica (IS.C) e a outra metade em condição ambiente (IS.A). Este procedimento foi escolhido para simular o impacto desse aditivo em uma estrutura construída que foi carregada logo após os 28 dias de cura habitual. As amostras de autocicatrizante ( $x \mathrm{x} . \mathrm{xA})$ foram comparadas com um grupo de controle do concreto comum (yy.yC) em todos os experimentos.

Ensaios de resistência a compressão, segundo a ABNT NBR 5739 (2007), foram realizados aos 28 dias nos corpos de prova curados em câmara úmida, dos grupos LB e IS. 


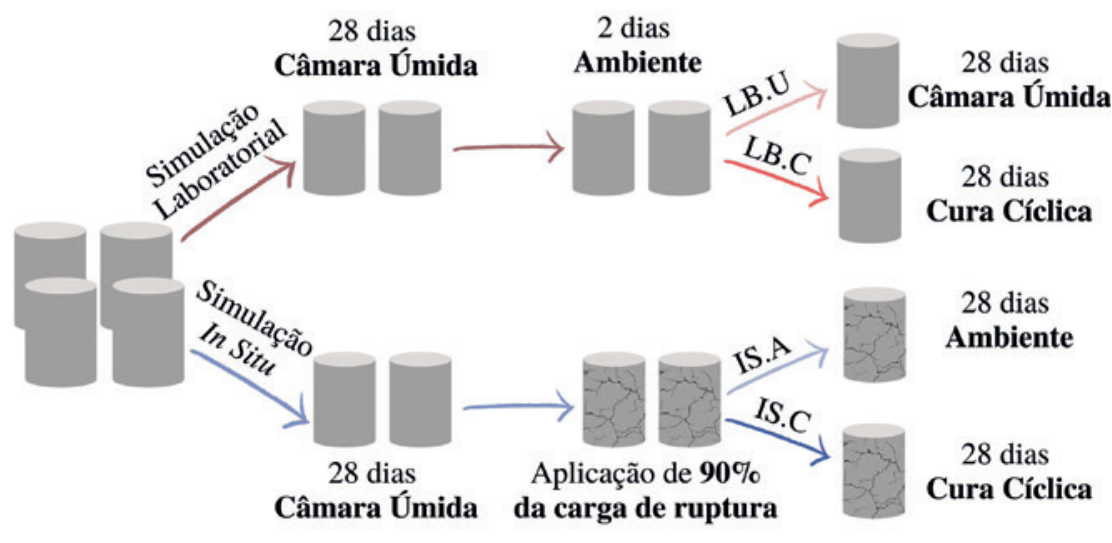

Figura 2

Diagrama dos diferentes métodos de cura aplicados em amostras de controle e de autocicatrizante

Após o período total de cura, as amostras foram cortadas em discos de $10 \mathrm{~cm} \times 5 \mathrm{~cm}$, aproveitou-se apenas a parte central de cada corpo de prova, sendo desprezados o topo e a base da amostra original. Em seguida foram submetidas ao teste de resistência à penetração de íons cloretos segundo a ASTM C 1202 (2005). Na Figura 3 é possível observar a célula lateral com o fio de resistência, já preparada para a colocação da amostra. À direita está o corpo de prova já cortado, antes de

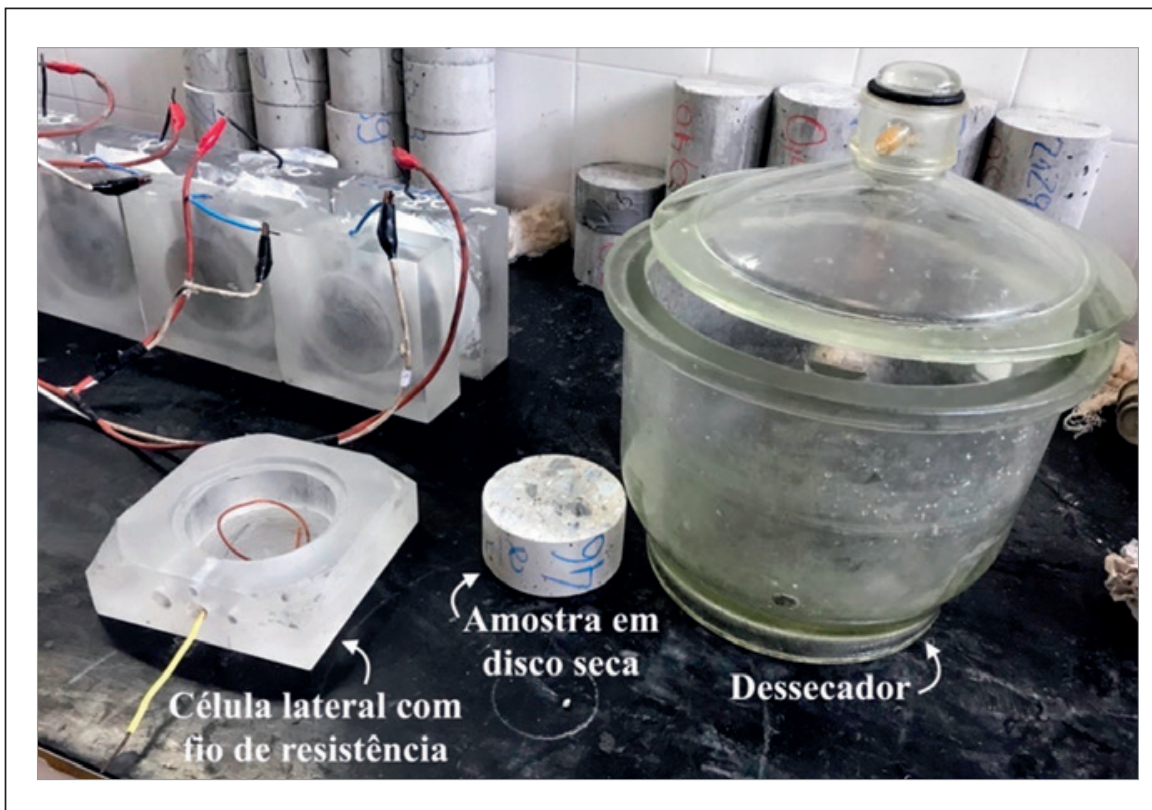

Figura 3

Equipamentos para preparação da amostra segundo o ensaio da ASTM C 1202 (2005) e amostra em disco com as medidas finais sua preparação para alocação na célula, e o dessecador utilizado durante o procedimento de preparação das amostras.

A configuração final do ensaio está ilustrada na Figura 4, em que os lados A e B estão preenchidos, respectivamente, com cloreto de sódio em solução de 3\% em massa e hidróxido de sódio 0,3 N, ambos preparados com água destilada. Uma tensão de $60 \mathrm{~V} \pm 0,1 \mathrm{~V}$ foi aplicada durante 6 horas, permitindo a determinação da carga passante em Coulombs. O material foi classificado seguindo a mesma norma, de acordo com a Tabela 1.

Após a obtenção da penetrabilidade de íons cloretos os espécimes ensaiados foram submetidos ao procedimento da norma NT BUILD 492 (1999), para a obtenção do coeficiente de migração de íons cloretos.

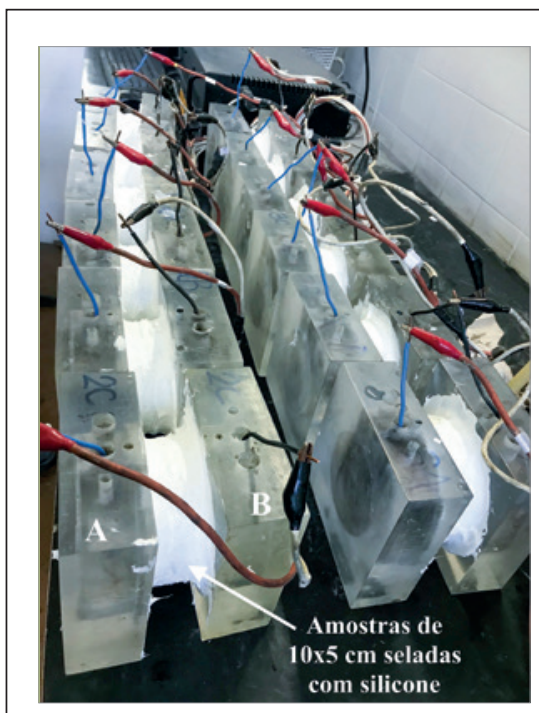

Figura 4

Configuração experimental final para 12 amostras, com uma solução de cloreto de sódio em A e hidróxido de sódio em $B$, de acordo com ASTM C 1202 (2005) 
Tabela 1 - Classificação ASTM C 1202 (2005) de penetrabilidade de íons cloretos

\begin{tabular}{|c|c|}
\hline $\begin{array}{c}\text { Carga passante } \\
{[C]}\end{array}$ & $\begin{array}{c}\text { Penetrabilidade } \\
\text { de ions cloretos }\end{array}$ \\
\hline$>4000$ & Alta \\
\hline 2000 a 4000 & Moderada \\
\hline 1000 a 2000 & Baixo \\
\hline 100 a 1000 & Muito baixo \\
\hline$<100$ & Insignificante \\
\hline
\end{tabular}

As amostras foram divididas axialmente e nitrato de prata na concentração de 0,1 M foi aplicado em sua superfície. A profundidade da penetração de íons cloretos tornou-se visível através de um resíduo branco, mostrado na Figura 5, sendo medido verticalmente de cinco a sete vezes em cada espécime. O coeficiente de migração foi calculado de acordo com a Equação 1.

\begin{tabular}{|c|}
$D_{n s s m}=\frac{0,0239 \cdot(273+T) \cdot L}{(U-2) \cdot t}$. \\
$\left(x_{d}-0,0238 \cdot \sqrt{\frac{(273+T) \cdot L \cdot x_{d}}{U-2}}\right)$
\end{tabular}

Onde: $D_{\text {nssm }}=$ coeficiente de migração no estado não estacionário $\left(x 10^{-12} \mathrm{~m}^{2} / \mathrm{s}\right) ; U=$ valor absoluto da voltagem aplicada (V); $\mathrm{T}=$ valor médio das temperaturas inicial e final na solução anódica $\left({ }^{\circ} \mathrm{C}\right)$; $\mathrm{L}=$ espessura da amostra $(\mathrm{mm})$; $x_{d}=$ valor médio das profundidades de penetração $(\mathrm{mm})$; e t = duração do teste (horas).

Com base no coeficiente de migração encontrado anteriormente e convertido em centímetros quadrados por ano, a penetração de íons cloretos $\left(\mathrm{cm}^{2}\right)$ foi estimada através da multiplicação desse coeficiente pelo número de anos previstos. A penetração na estrutura foi estimada entre um e cinquenta anos de construção, tempo habitual de durabilidade estipulado para uma nova estrutura.

\section{RESULTADOS E DISCUSSÃO}

A resistência à compressão aos 28 dias está apresentada na Tabela 2, sendo que a média para as amostras LB foi de $44 \mathrm{MPa}$ e para as amostras IS de $49 \mathrm{MPa}$. Foi possível notar que a utilização do aditivo não gerou nenhuma alteração na resistência à compressão, os valores obtidos para cada moldagem (LB e IS) são muito próximos ao comparar o concreto de controle e o autocicatrizante. Reafirmando a constatação já realizada por outros autores [4].

De acordo com a ASTM C 1202 (2005), todas as amostras são classificadas com baixa penetração de íons cloretos (Tabela 3), indicando uma boa resistência a ambientes agressivos, independentemente do método de cura. A baixa penetrabilidade dos íons cloretos pode estar relacionada à alta resistência à compressão, como já demonstrado em trabalhos anteriores [2].

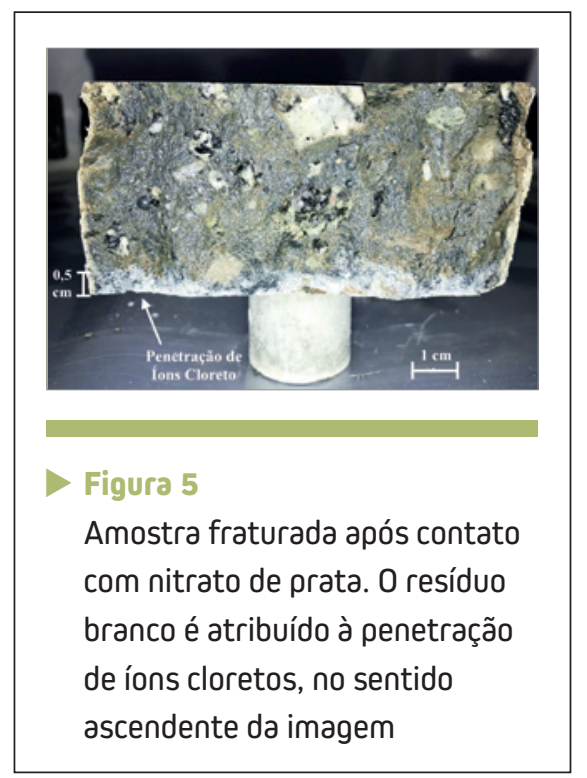

Ainda na Tabela 3, é possível observar que, mesmo estando na mesma classificação de penetração de íons cloretos, a carga passante para o concreto autocicatrizante é superior ao concreto de controle em 3 dos 4 grupos em análise. No entanto, as profundidades de penetração não seguem o mesmo padrão, sendo maior em todos os corpos de prova de controle (Figura 6). Essa discrepância pode estar relacionada ao aumento da carga passante com a presença de outros tipos de íons, que podem não ser os íons cloretos.

Tabela 2 - Resistência à compressão aos 28 dias para as curas LB e IS de amostras de controle e autocicatrizante

\begin{tabular}{|c|c|c|c|c|}
\hline \multirow[b]{2}{*}{ Amostra } & \multicolumn{2}{|c|}{ LB } & \multicolumn{2}{|c|}{ IS } \\
\hline & $\begin{array}{l}\text { Resistência } \\
\text { [MPa] }\end{array}$ & $\begin{array}{l}\text { Média } \\
\text { [MPa] }\end{array}$ & $\begin{array}{l}\text { Resistência } \\
\text { [MPa] }\end{array}$ & $\begin{array}{l}\text { Média } \\
\text { [MPa] }\end{array}$ \\
\hline \multirow{3}{*}{ Controle } & 43,52 & \multirow{3}{*}{44,00} & 46,80 & \multirow{3}{*}{48,73} \\
\hline & 42,89 & & 48,10 & \\
\hline & 45,58 & & 51,30 & \\
\hline \multirow{3}{*}{ Autocicatrizante } & 44,68 & \multirow{3}{*}{44,07} & 48,00 & \multirow{3}{*}{48,80} \\
\hline & 43,12 & & 51,10 & \\
\hline & 44,42 & & 47,30 & \\
\hline
\end{tabular}


Tabela 3 - Carga passante

média de acordo com ASTM C

1202 (2005)

\begin{tabular}{|c|c|c|}
\hline \multirow{2}{*}{$\begin{array}{l}\text { Método } \\
\text { de } \\
\text { cura }\end{array}$} & \multicolumn{2}{|c|}{$\begin{array}{l}\text { Carga passante } \\
\text { [Coulomb] }\end{array}$} \\
\hline & Controle & Autocicatrizante \\
\hline LB.U & 1168 & 1204 \\
\hline LB.C & 1099 & 1086 \\
\hline IS.A & 1087 & 1166 \\
\hline IS.C & 1413 & 1797 \\
\hline
\end{tabular}

A utilização do aditivo pode introduzir formas iônicas diferentes, com concentrações maiores de íons, consequentemente gerando uma maior carga passante. O aumento dessa carga não está relacionado com a capacidade do aditivo de reduzir a penetração de íons cloretos no material, propriedade que foi mantida em todos os corpos de prova. Estudos mais aprofundados são necessários para um melhor entendimento desse processo.

As profundidades de penetração de íons cloretos (Figura 6) mostram que a LB.UA e LB.CA foram reduzidas em 5,4\% e 15,7\% em relação ao grupo de controle, enquanto no IS.AA e IS.CA foram reduzidas em 12,0\% e 17,3\% com a mesma referência. Em todos os casos, as amostras autocicatrizantes apresentaram diminuição da profundidade de penetração quando comparados com o grupo de controle. Além disso, a cura cíclica teve os melhores resultados para ambas as situações, o que pode estar relacionado com uma melhor interação entre o material e o ambiente, permitindo que exista água suficiente para iniciar as reações, além de outros compostos necessários para essas reações, que se encontram presentes no ar ambiente.

É importante destacar o aumento significativo da resistência à penetração das amostras fissuradas, enfatizando a melhoria do IS.AA, que foi capaz de dobrar a resistência à penetração quando comparado ao LB.UA, independentemente do menor acesso à água. Esse efeito pode ser explicado por uma inten-

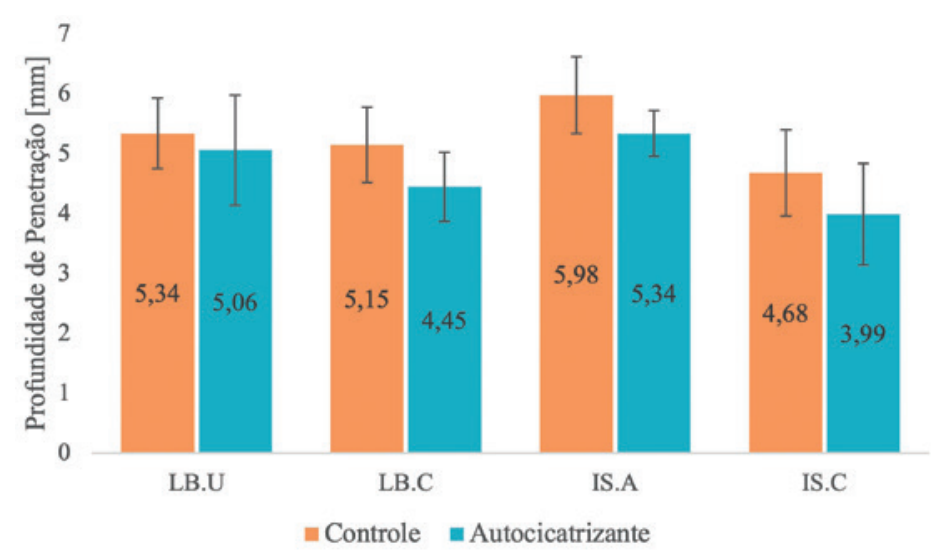

Figura 6

Profundidade média de penetração de íons cloretos e desvio padrão para amostras de controle e autocicatrizante em todos os tipos de cura

sificação nas reações do aditivo no concreto autocicatrizante fissurado, sendo respaldado pelo fato de que o concreto exposto às condições ambientais pode absorver uma pequena quantidade de água da umidade no ar. Essa possibilidade foi relatada anteriormente por Nasim, Dewangan e Deo [5].

O coeficiente de migração de íons cloretos foi estimado para cada espécime (Tabela 4). Com base nesses resultados, foi possível prever a profundidade de penetração de íons cloretos nesses materiais, representada nas Figuras 7 e 8 . Nas condições laboratoriais, amostras de concreto autocicatrizante em cura cíclica (LB. CA) tiveram a melhor resistência à penetração de íon cloreto ao longo do tempo. A cura cíclica melhorou o desempenho de todas as amostras, independentemente do uso de aditivo, resultando em profundidade de penetração semelhante em LB.CC e LB.UA. O material sem aditivo e em cura na câmara úmida (LB.UC) teve a maior penetração de íons cloretos, o que pode estar associado a menor quantidade de água presente na amostra, além de não possuir a contribuição do aditivo.

A estimativa da penetração de ín cloretos para a cura IS mostrou que o IS.CA seria o melhor tipo de cura e IS.AC, o pior, como anteriormente observado para LB. No entanto, IS.AC teve um ligeiro aumento quando comparado ao LB.UC e IS.AA, não coincidindo com o IS.CC, como na cura LB. Ambas as diferenças podem ser decorrentes da falta de contato com a água, atestando que o uso do aditivo redutor de permeabilidade por cristalização 
> Tabela 4 - Coeficientes de migração calculados a partir da profundidade de penetração de acordo com NT BUILD 492 (1999)

\begin{tabular}{|ccccc|}
\hline $\begin{array}{l}\text { Método } \\
\text { de cura }\end{array}$ & $\begin{array}{c}\text { Coeficiente de migração } \\
{\left[\mathbf{1 0}^{-12} \mathbf{~ m}^{2} / \mathrm{s}\right]}\end{array}$ & \multicolumn{2}{c|}{$\begin{array}{c}\text { Coeficiente de migração } \\
\text { [cm²/ano] }\end{array}$} \\
\hline LB.U & 4,54 & 4,28 & 1,43 & 1,35 \\
\hline LB.C & 4,36 & 3,71 & 1,37 & 1,17 \\
\hline IS.A & 5,14 & 4,53 & 1,62 & 1,43 \\
\hline IS.C & 3,92 & 3,29 & 1,24 & 1,04 \\
\hline
\end{tabular}
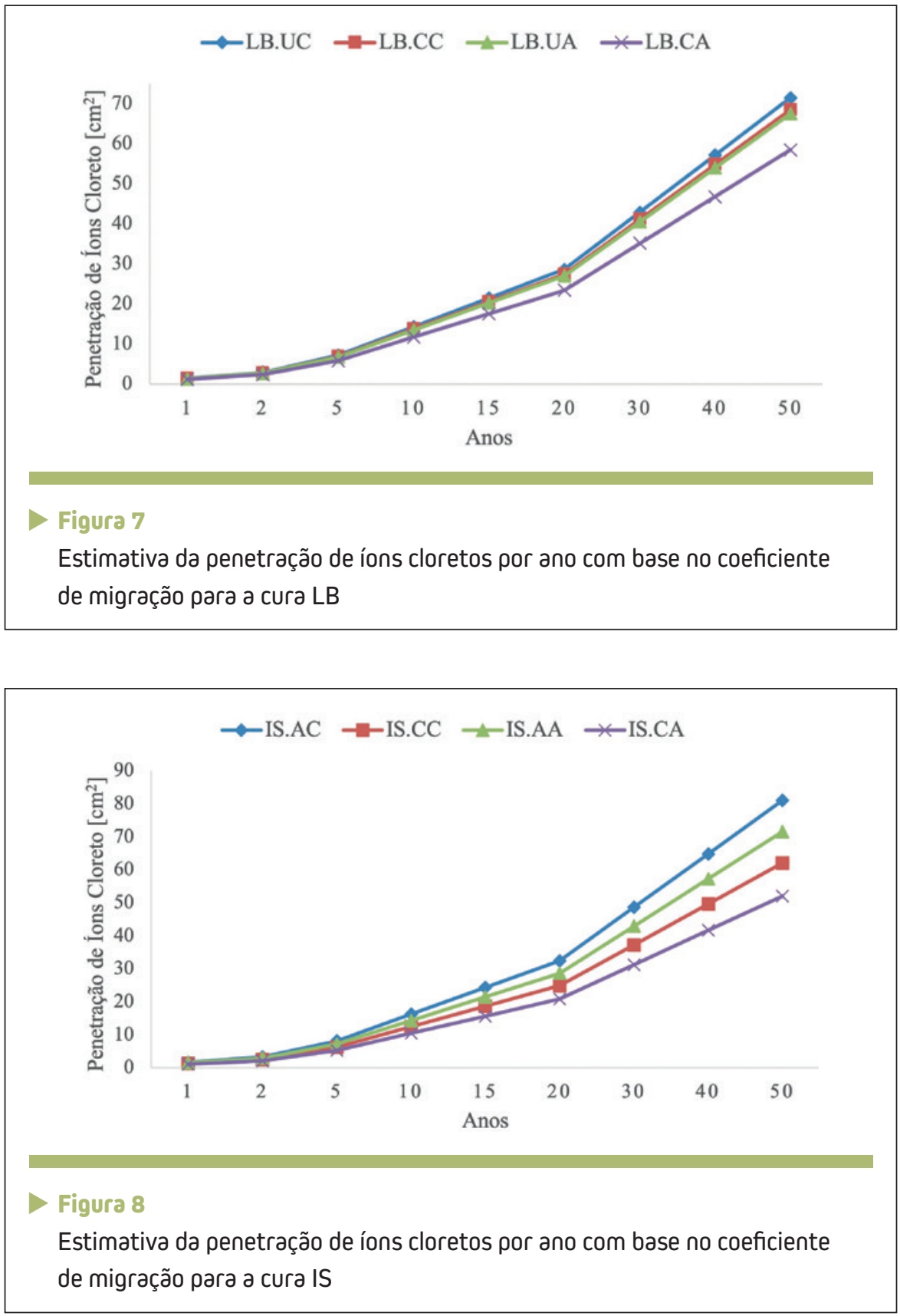

capilar no concreto pode melhorar a resistência à permeabilidade do material quando na presença de água.

Sendo assim, mesmo com valores próximos, é possível observar que o uso do aditivo redutor de permeabilidade por cristalização capilar pode vir a aumentar a resistência do concreto à penetração de íons cloretos, aumentando a durabilidade de uma estrutura em contato com este agente agressivo. Além disso, o concreto autocicatrizante possui uma tendência em melhorar as propriedades do material quando comparado com o concreto de controle, desde que tenham sido submetidos ao mesmo tipo de cura. No entanto, o concreto comum pode ter um aumento na resistência à penetração de íons cloretos ao ser curado em contato com a água, independentemente do uso do aditivo, resultado que está de acordo com a capacidade de autocicatrização autógena do concreto.

\section{CONCLUSÃO}

$\mathrm{O}$ aditivo redutor de permeabilidade por cristalização capilar para concreto autocicatrizante foi aplicado em diferentes tipos de cura, com procedimento laboratorial (LB) e reprodução das condições in situ (IS), realizada com amostras fissuradas. A cura laboratorial foi feita em câmara úmida (LB.U) e na cura cíclica (LB.C), enquanto a reprodução da condição in situ ocorreu em ambiente (IS.A) e cura cíclica (IS.C). Cada condição de cura possuía um grupo de controle para comparação. Todas as amostras apresentaram baixa penetração de íons cloretos, o que pode estar relacionado com a alta resistência à compressão obtida. A cura 
cíclica teve os melhores resultados independentemente do uso de aditivo, evidenciando que a água é essencial para todos os processos de autocicatrização, sendo autógena ou autônoma. No entanto, ao comparar amostras nas mesmas condições de cura, notou-se uma propensão à meIhora do concreto autocicatrizante, indicando que o uso do aditivo é capaz de reduzir a penetrabilidade de íons cloretos, mesmo quando a presença de água é limitada. A longo prazo, as amostras autocicatrizantes em cura cíclica, fissuradas ou não, tiveram a menor penetração de íons estimada para cinquenta anos, demostrando uma possível ligação entre a utilização do concreto autocicatrizante e um aumento na durabilidade.

\section{AGRADECIMENTOS}

Agradecemos a empresa Penetron Brasil Ltda por doar o aditivo redutor de permeabilidade por cristalização capilar e aos laboratórios da Associação Brasileira de Cimento Portland (ABCP) e Testin Tecnologia de Materiais Ltda por fornecerem os ensaios realizados nesta pesquisa.

\section{REFERÊNCIAS BIBLIOGRÁFICAS}

[1] Sisomphon K, Copuroglu 0, Koenders EAB. Effect of exposure conditions on self healing behavior of strain hardening cementitious composites incorporating various cementitious materials. Constr Build Mater 2013; 42: 217-224

[2] Ourives CN, Araújo M, Freire PS. Estudo De Caso : Impermeabilização Do Subsolo Do Condomínio Adelaide. In: $13^{\circ}$ Simpósio Brasileiro de Impermeabilização. São Paulo: Instituto Brasileiro de Impermeabilização, p. 11.

[3] Aire C, Reyes A. Durable concrete specification development and implementation for the New International Airport of Mexico. Case Stud Constr Mater $2019 ; 11: 13$.

[4] Helene P, Guignone G, Vieira G, et al. Avaliação da penetração de cloretos e da vida útil de concretos autocicatrizantes ativados por aditivo cristalino. Rev IBRACON Estruturas e Mater 2018; 11: 554-563.

[5] Nasim M, Dewangan UK, Deo S V. Autonomous healing in concrete by crystalline admixture: A review. Mater Today Proc 2020; 32: 638-644.

\section{O best seller da engenharia de materiais de construção não pode faltar}

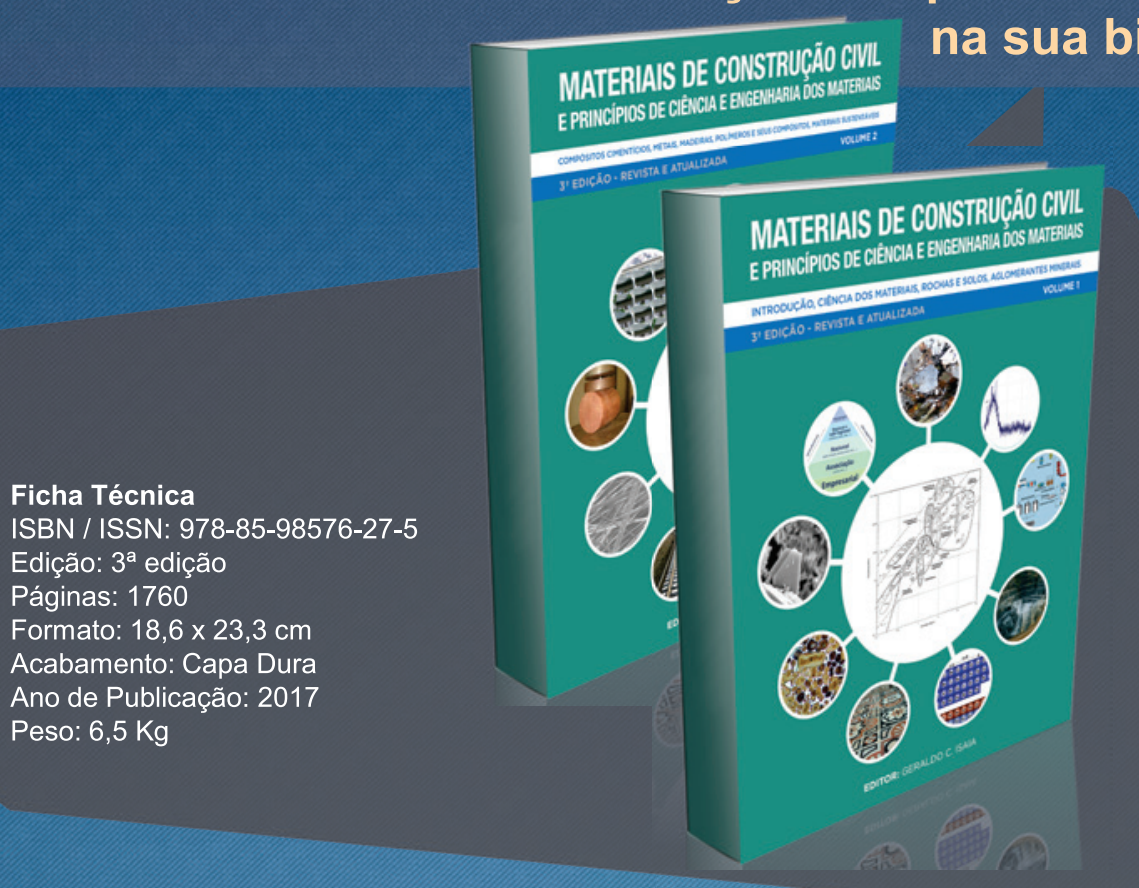

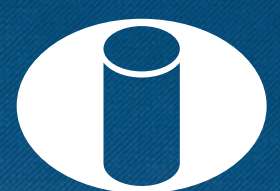

IBRACON
O livro "Materiais de Construção Civil e Princípios de Ciência e Engenharia dos Materiais" é a mais completa fonte de consulta para estudantes, professores e profissionais da engenharia.

Dividido em dois volumes, o livro é composto por 52 capítulos escritos por 86 reconhecidos especialistas brasileiros, totalmente referenciado nas normas brasileiras vigentes e de acordo com as práticas nacionais da mais alta qualidade da engenharia civil em vigor. 